\title{
Correlation between Iron Profile of Pregnant Women and Their Newborns: A Cross Sectional Study
}

\author{
Gorav Kumar', Gunvanti Meena ${ }^{2}$, Bhagwati Lal Bhati ${ }^{3}$ \\ ${ }^{1}$ Senior Resident, Department of Paediatrics, Government Medical College \& General Hospital, Dungarpur, Rajasthan, India, ${ }^{2}$ Assistant Professor, Department of \\ Obstetrics and Gynaecology, Govt. Medical College \& General Hospital, Dungarpur, Rajasthan, India, ${ }^{3}$ Junior Resident, Department of Paediatrics, Government \\ Medical College \& General Hospital, Dungarpur, Rajasthan, India.
}

\section{Abstract}

Background: Maternal anemia leads to many adverse effects on the fetuses fetal complications. The mechanisms leading to increased morbidity include a decreased oxygen delivery capacity and the dysfunction of enzymes. The aim of this study to relationship between iron status of pregnant mothers and their newborns using a combination of several hematological parameters. Subjects and Methods: A hospital based descriptive type of observational study done on 50 singleton primi pregnant women at term gestation (37-42 weeks) admitted to labour room in government Medical College and general Hospital, Dungarpur (Raj.). General physical examination was done meticulously to assess maternal conditions regarding anemia such as nutritional status, pallor, edema and glossitis. Results: Our study showed that the male to female ratio was 1.28:1. Normal birth weight in baby was seen in $80 \%$ of cases. The spearman correlation of hemoglobin concentration was statistical significant in the newborns of mothers with hemoglobin concentration $\left(r 2=0.14,0.50,0.61\right.$ respectively and $P=0.0076^{* *}$, $0.009 * * \& 0.02 * *$ respectively). The newborns ferritin level has significant correlation with hemoglobin $(r 2=0.142, P<0.001)$ and ferritin $(r 2=0.253, P<0.001)$ levels of their mothers. Conclusion: we can conclude that maternal anemia may have an effect on the iron stores of newborns.

Keywords: Iron Deficiency Anemia, Hemoglobin, Serum Ferritin, Newborns.

Corresponding Author: Dr. Gunvanti Meena, Assistant Professor, Department of Obstetrics and Gynaecology, Govt. Medical College \& General Hospital, Dungarpur, Rajasthan, India.

Received: June 2019

Accepted: July 2019

\section{Introduction}

Iron-deficiency anemia in pregnancy may have a serious effect on the health of both the mother and the baby; anemia can increase maternal and infant morbidity and mortality. The mechanisms leading to increased morbidity include a decreased oxygen delivery capacity and the dysfunction of enzymes. $^{[1]}$

The cause of iron-deficiency anemia in pregnancy is a complex combination of increased iron demand, low iron intake, and chronic blood loss. Many factors have been associated with the risk of iron-deficiency in pregnancy, eg nutritional status, socioeconomic variables, culture, age, educational status, parity, spacing of pregnancies, and the use of contraceptive devices.

Maternal anemia leads to many adverse effects on the fetuses fetal complications such as low birth weight, preterm deliveries, developmental anomalies and even neonatal death are some of them. Prevention and management of maternal anemia is crucial to prevent morbidity and mortality of the fetus. There are four approaches towards prevention of anemia in pregnancy. These include dietary changes to increase the iron levels, iron supplementation, food fortification and other general public health measures. These measures include education in child spacing, improving the nutritional status of women, sanitation, immunization, control of diarrheal diseases, etc. ${ }^{[2]}$

It is still not clear whether iron deficiency in pregnant women might lead to a deficient iron status of their children. Many studies have supported the belief that iron transport from the mother to their fetus occurs independently of maternal iron levels, and that it might even induce deficiency in the mother as a result of fetal "parasitism". However, later studies have questioned this belief and suggested that maternal iron deficiency can cause depletion of fetal iron stores. No consensus regarding this subject has been reached thus far. ${ }^{[3,4]}$ The aim of this study to relationship between iron status of pregnant mothers and their newborns using a combination of several hematological parameters.

\section{Subjects and Methods}

A hospital based descriptive type of observational study done on 50 singleton primi pregnant women at term gestation (37-42 weeks) admitted to labour room in government Medical College and general Hospital, 
Dungarpur (Raj.)

Inclusion Criteria

- All singleton primi pregnant women at term gestation (37-42 weeks) admitted to labour room.

- All women who give consent to be a part of study

Exclusion Criteria

- Women with systemic disease such as hypertension, diabetes mellitus, heart disease and other chronic medical diseases.

- Women with congenitally malformed fetus or IUFD.

General physical examination was done meticulously to assess maternal conditions regarding anemia such as nutritional status, pallor, edema and glossitis. Systemic examination was done for respiratory and cardiovascular system.

Obstetrical examination was done for fundal height and estimation of gestational age.

\section{Statistical Analysis}

We entered the data from the analyzers and questionnaire into Microsoft Excel and analyzed it using SPSS version 16.0. Since all of the analytes studied were not normally distributed, nonparametric tests were applied.

\section{Results \& Discussion}

Our study showed that the male to female ratio was 1.28:1. Normal birth weight in baby was seen in $80 \%$ of cases [Table 1].

Our study showed that the mean value of different level of hemoglobin concentration was higher in newborn as compared to mother's hemoglobin concentration. The spearman correlation of hemoglobin concentration was statistical significant in the newborns of mothers with hemoglobin concentration $(r 2=0.14,0.50,0.61$ respectively and $P=0.0076^{* *}, 0.009^{* *} \& 0.02^{* *}$ respectively) with fall in the hemoglobin concentration in the mother, there is a statistical significant fall in the hemoglobin concentration in the newborn in all aspect 9-11 $\mathrm{gm} / \mathrm{dl}$ groups of the maternal cases.

Maria Jesus Gaspar, Rosa Maria Ortega, Olga Moreiras (1993) 5 observed statistically significant correlations between hemoglobin and hematocrit values of the mother with erythrocyte count, hemoglobin and hematocrit values of her child and between serum iron of mother and child.

The newborns ferritin level has significant correlation with hemoglobin $(r 2=0.142, P<0.001)$ and ferritin $(r 2=0.253$,
$P<0.001)$ levels of their mothers. That is to say, when ferritin level fixation in moms was diminished the ferritin focus in infant was additionally essentially diminished.

P. Macphail, et al (1980), ${ }^{[6]}$ found a weak correlation between cord and maternal serum ferritin concentrations was demonstrated $(r=0.21, \mathrm{P}<0.05)$ but its biological significance is questionable.

J. Puolakka, O. Jänne \& R. Vihko (1981), ${ }^{[7]}$ found serum ferritin concentration of the newborn babies (mean 222 $\mu \mathrm{g} / \mathrm{l})$ born to the mothers with a low serum ferritin content at term (mean $28 \mu \mathrm{g} / \mathrm{l})$ was significantly lower $(\mathrm{p}<0.05)$ than that for those (mean $324 \mu \mathrm{g} / \mathrm{l}$ ) born to the mothers with a normal ferritin concentration (mean $102 \mu \mathrm{g} / \mathrm{l}$ ).

Maria Jesus Gaspar, Rosa Maria Ortega, Olga Moreiras (1993) 5 found that the blood levels in the umbilical cord did not decrease until the ferritin value of the mother was $<12$ $\mu \mathrm{g} / 1$. Under these conditions the ferritin levels in the umbilical cord blood $(80.4 \mu \mathrm{g} / 1)$ were significantly lower than in those newborn infants whose mother had adequate ferritin levels $(123 \mu \mathrm{g} / 1)$.

Several investigators have determined the correlation between hemoglobin and ferritin parameters of newborns and their mothers; however, the results vary from study to study. Kumar et al., ${ }^{[8]}$ for example, have showed that maternal ferritin levels had significant correlations with Hgb levels ( $r s=+0.488 ; P<0.001)$ and ferritin $(r s=$ $+0.440 ; P<0.001)$ in cord blood. Singla et al. have also found that maternal serum ferritin was significantly correlated with cord blood Hgb $(r s=+0.390, P<0.01)$ and cord serum ferritin $(r s=+0.523 ; P<0.001){ }^{[9]}$

Median hemoglobin and ferritin concentrations were significantly lower in newborns delivered from anemic mothers compared to non-anemic mothers. Additionally newborns hemoglobin and ferritin concentration had a significant correlation with hemoglobin and ferritin concentration of the mothers.

Table 1: Distribution of cases according to demographic profile of new born.

\begin{tabular}{|l|l|l|l|}
\hline Demographic profile & No. of subjects & Percentage \\
\cline { 2 - 4 } & Male & 28 & $56 \%$ \\
\cline { 2 - 4 } & Female & 22 & $44 \%$ \\
\hline \multirow{3}{*}{$\begin{array}{l}\text { Baby } \\
\text { weight }\end{array}$} & Normal birth weight & 40 & $80 \%$ \\
\cline { 2 - 4 } $\begin{array}{l}\text { APGAR } \\
\text { score }\end{array}$ & Low birth weight & 10 & $20 \%$ \\
\cline { 2 - 4 } & 9 & 21 & $42 \%$ \\
\cline { 2 - 4 } & 10 & 15 & $30 \%$ \\
\hline
\end{tabular}

Table 2: Correlation of hemoglobin concentration in mother with newborn

\begin{tabular}{|l|l|l|l|l|l|}
\hline \multirow{2}{*}{ Hb. concentration } & Mothers & Newborn & \multirow{2}{*}{ r2 } & \multirow{2}{*}{ p-value } \\
\cline { 2 - 5 } & No. & Mean \pm SD & Mean \pm SD & & \\
\hline$>11 \mathrm{~g} / \mathrm{dl}$ & 35 & $12.77 \pm 1.423$ & $16.75 \pm 1.083$ & 0.611 & $0.0217^{*}$ \\
\hline $9.1-11 \mathrm{~g} / \mathrm{dl}$ & 6 & $10.12 \pm 0.55$ & $15.15 \pm 2.105$ & 0.353 & 0.0664 \\
\hline $7.1-9 \mathrm{~g} / \mathrm{dl}$ & 5 & $7.340 \pm 0.612$ & $15.03 \pm 2.006$ & 0.578 & $0.0092^{* *}$ \\
\hline$<7 \mathrm{~g} / \mathrm{dl}$ & 4 & $6.003 \pm 0.317$ & $14.12 \pm 1.59$ & 0.143 & $0.0076^{* *}$ \\
\hline
\end{tabular}


Table 3: Correlation of serum ferritin level in mother with newborn

\begin{tabular}{|l|l|l|l|l|l|}
\hline \multirow{2}{*}{ Serum ferritin } & Mothers & Newborn & \multirow{2}{*}{ r2 } & \\
\cline { 2 - 5 } & No. & Mean \pm SD & Mean \pm SD & & \\
\hline$>15 \mathrm{ng} / \mathrm{ml}$ & 43 & $45.23 \pm 49.02$ & $142.1 \pm 75.07$ & 0.142 & $<0.001$ \\
\hline$<15 \mathrm{ng} / \mathrm{ml}$ & 7 & $12.43 \pm 3.114$ & $108.1 \pm 50.46$ & 0.253 & $<0.001$ \\
\hline
\end{tabular}

\section{Conclusion}

Anaemia is a serious health problem in India where the life of pregnant women and her child are endangered. It is directly proportional to parity, less spacing between pregnancies and related to lower educational status. Median hemoglobin and ferritin concentrations were significantly lower in newborns delivered from anemic mothers compared to non-anemic mothers.

\section{References}

1. WHO: Reducing Risks, Promoting Healthy Life, The World health report. Geneva, Switzerland; 2001.

2. Koura GK, Ouedraogo S, Le Port A, Watier L, Cottrell G, Guerra J et al. Anaemia during pregnancy: impact on birth outcome and infant haemoglobin level during the first 18 months of life. Trop Medi Int Health. 2012 Mar;17(3):283-91.

3. Gyorkos, T. W., Gilbert, N. L., Larocque, R. and Casapía, M. (2011),
Trichuris and hookworm infections associated with anemia during pregnancy. Tropical Medicine \& International Health, 16: 531-537. Doi: 10.1111/j.1365-3156.2011.02727.x

4. University of Health Science, Ministry of Education, Vientiane, Lao PDR.A study of anemia in pregnant women with Plasmodium falciparum at district hospitals in Vientiane, Lao PDR. The Southeast Asian Journal of Tropical Medicine and Public Health. 2000;31 Suppl 1:91-8.

5. Gaspar, M. J., Ortega, R. M. and Moreiras, O. Relationship between iron status in pregnant women and their newborn babies. Acta Obstetricia et Gynecologica Scandinavica. (1993); 72: 534-537.

6. Puolakka J, Jänne O, Vihko R. Evaluation by serum ferritin assay of the influence of maternal iron stores on the iron status of newborns and infants [Acta Obstet Gynecol Scand] Suppl. 1980;95:

7. Macphail, A. P., Charlton, R. W., Bothwell, T. H. and Torrance, J. D. The Relationship between Maternal and Infant Iron Status. Scandinavian Journal of Haematology, (1981); doi:10.1111/j.16000609.1981.tb01379.

8. Kumar, A. K. Rai, S. Basu, D. Dash, and J. S. Singh. Cord blood and breast milk iron status in maternal anemia," Pediatrics 2008; 121(3), pp. e673-e677.

9. P. N. Singla, M.Tyagi, R. Shankar, D.Dash, and A.Kumar, Fetal iron status in maternal anemia, Acta Paediatrica 1996; 85(11), 1327-30.

Copyright: (C) the author(s), 2019. It is an open-access article distributed under the terms of the Creative Commons Attribution License (CC BY 4.0), which permits authors to retain ownership of the copyright for their content, and allow anyone to download, reuse, reprint, modify, distribute and/or copy the content as long as the original authors and source are cited.

How to cite this article: Kumar G, Meena G, Bhati BL. To Correlation between Iron Profile of Pregnant Women and Their Newborns: A Cross Sectional Study. Asian J. Med. Res. 2019;8(3):PE01-PE03.

DOI: dx.doi.org/10.21276/ajmr.2019.8.3.PE1

Source of Support: Nil, Conflict of Interest: None declared. 